\author{
Mathijs Vogelzang \\ Bert G. Loef \\ Joost G. Regtien \\ Iwan C. C. van der Horst \\ Hein van Assen \\ Felix Zijlstra \\ Maarten W. N. Nijsten
}

\title{
Computer-assisted glucose control in critically ill patients
}

Received: 21 December 2007

Accepted: 10 March 2008

Published online: 4 April 2008

(C) The Author(s) 2008

Electronic supplementary material

The online version of this article (doi:10.1007/s00134-008-1091-y) contains supplementary material, which is available to authorized users.

\author{
M. Vogelzang ( $)$ B. G. Loef • \\ J. G. Regtien · H. van Assen . \\ M. W. N. Nijsten \\ University of Groningen, Department of \\ Critical Care, University Medical Center, \\ 9700 RB Groningen, The Netherlands \\ e-mail: m.vogelzang@ thorax.umcg.nl \\ Tel.: +31-50-3616161 \\ Fax: +31-50-3614391 \\ I. C. C. van der Horst · F. Zijlstra \\ University of Groningen, Department of \\ Cardiology, University Medical Center, \\ 9700 RB Groningen, The Netherlands
}

\begin{abstract}
Objective: Intensive insulin therapy is associated with the risk of hypoglycemia and increased costs of material and personnel. We therefore evaluated the safety and efficiency of a computer-assisted glucose control protocol in a large population of critically ill patients. Design and setting: Observational cohort study in three intensive care units ( 32 beds) in a 1,300-bed university teaching hospital. Patients: All 2,800 patients admitted to the surgical, neurosurgical, and cardiothoracic units; the study period started at each ICU after implementation of Glucose Regulation for Intensive Care Patients (GRIP), a freely available computer-assisted glucose control protocol. Measurements and results: We analysed compliance in relation to recommended insulin pump rates and glucose measurement frequency. Patients were on GRIP-ordered pump rates $97 \%$ of time. Median meas-
\end{abstract}

urement time was 5 min late (IQR $20 \mathrm{~min}$ early to $34 \mathrm{~min}$ late). Hypoglycemia was uncommon (7\% of patients for mild hypoglycemia, $<3.5 \mathrm{mmol} / \mathrm{l} ; 0.86 \%$ for severe hypoglycemia, $<2.2 \mathrm{mmol} / \mathrm{l}$ ). Our predefined target range (4.0-7.5 mmol/l) was reached after a median of $5.6 \mathrm{~h}$ (IQR 0.2-11.8) and maintained for $89 \%$ (70-100\%) of the remaining stay at the ICU. The number of measurements needed was 5.9 (4.8-7.3) per patient per day. In-hospital mortality was $10.1 \%$. Conclusions: Our computer-assisted glucose control protocol provides safe and efficient glucose regulation in routine intensive care practice. A low rate of hypoglycemic episodes was achieved with a considerably lower number of glucose measurements than used in most other schemes.

Keywords Insulin - Glucose · Critically ill $\cdot$ Computer decision support

\section{Introduction}

Glucose control with intensive insulin therapy in critically ill medical and surgical patients reduces morbidity and mortality $[1,2]$. However, this therapy carries the risk of hypoglycemia. Although little is known about the impact of hypoglycemia, cases with severe sequelae have been reported [3-5]. Recently a retrospective review found that the occurrence of a single episode of hypoglycemia is related to mortality [6]. Due to the high rate of insulin-induced hypoglycemia a multicenter trial has been stopped, and negative results have led to debate about the overall benefit of glucose control [7, 8]. Therefore a meticulous scheme of glucose measurements and subsequent insulin-dosing adjustments must be implemented. Such a scheme should lead to adequate control with as few glucose measurements as possible with minimal risk of hypoglycemia.

Many insulin infusion protocols have been proposed, but performance is difficult to compare [9], and the size of reported patient cohorts is often small. As hypoglycemia is and should be a rare event, no firm conclusions can be drawn from small populations. Furthermore, a research setting in which a protocol is tested on selected patients 
may not reflect the performance of a protocol when used in routine practice. We implemented a computer-assisted glucose control system in routine practice and evaluated its safety and efficiency in a large cohort of unselected consecutive patients in three ICUs.

\section{Materials and methods}

\section{GRIP computer program}

The Glucose Regulation for Intensive Care Patients (GRIP) computer program gives recommendations on exact insulin pump rates and glucose measurement frequency for all patients. It also acts as watchdog against overdue measurements. Initial results and a description of the GRIP computer program have previously been reported [10]. In short, the GRIP program is installed on a computer directly next to the point of care blood gas analyzer. By default the computer shows an overview of the ICU. The colors of the beds make clear whether a specific action (such as taking a new blood glucose or modifying an insulin pump) should be performed at a certain bed. New glucose values are automatically queried from the hospital information system. These values are combined with clinical data obtained from the nurse, and recommendations on both the insulin pump rate and the measurement interval can be calculated at any moment. The algorithm employed by GRIP is based on both the level and the change in recent glucose values. A more detailed description of the algorithm is given in the accompanying Electronic Supplementary Material. GRIP was designed with practical applicability in mind; where possible, we aimed at limiting the number of blood glucose measurements needed and thus the time spent on glucose control. The total turn-around time for a nurse, from glucose measurement to final pump change was measured to be $4 \mathrm{~min}$.

In 2005 we implemented an improved version that incorporates more safety features, such as label printing, rendering the entire procedure paperless. The complete source code of the GRIP computer program is freely available from the website http://grip-glucose.sf.net/. The insulin dosing of GRIP is flexible with regard to its target value. In view of the debated value of aiming for true normoglycemia $(4.4-6.1 \mathrm{mmol} / \mathrm{l})$, the medical directors (M.N., B.L., J.R.) preferred a more lenient glucose range of $4.0-7.5 \mathrm{mmol} / \mathrm{l}$, and therefore GRIP was configured to aim for a glucose level of $6.5 \mathrm{mmol} / 1$. It should be noted that changing the algorithm's target value is trivial.

\section{Implementation of GRIP}

All ICUs that have implemented GRIP are part of the University Medical Center of Groningen, a 1,300-bed tertiary university hospital. All three ICUs are closedformat ICUs with a nursing to patient ratio of one-to-one. The three units are teaching general surgery, anesthesiology, and internal medicine residents, and fellows in intensive care medicine. GRIP was first implemented at the surgical ICU [10], followed by the cardiothoracic and neurosurgical ICU. In dialog with staff the initial target level was $7.0 \mathrm{mmol} / \mathrm{l}$ for the cardiothoracic ICU and $7.5 \mathrm{mmol} / \mathrm{l}$ for the neurosurgical ICU. Nurses were trained by a "teach-the-teacher" principle, where two or three nurses of each ICU were trained at the surgical ICU, after which they taught the colleagues at their own unit. After a run-in period the GRIP target level was lowered to $6.5 \mathrm{mmol} / \mathrm{l}$.

\section{Patients}

We included 2,800 admissions with 73,188 glucose measurements for analysis; Table 1 presents patients' characteristics. We recorded baseline demographics, reason for admission, and severity of illness as measured by Acute Physiology and Chronic Health Evaluation (APACHE) II scores [median 14, interquartile range (IQR) 10-19]. We excluded the patients who were treated by GRIP in any of the run-in periods. Figure 1 shows a patient selection diagram. All patients were managed by GRIP. Orders of GRIP could be overruled at the discretion of the physician at any time, or a patient could be taken out of GRIP altogether. The latter happened structurally with patients who had recovered enough to be taking meals. During intermittent invasive interventions insulin was stopped. The local institutional review board approved this study.
Fig. 1 Time chart of patient inclusion per ICU. The dark colored squares indicate a 'run-in' period. The patients treated by GRIP in these periods were not analyzed in this study

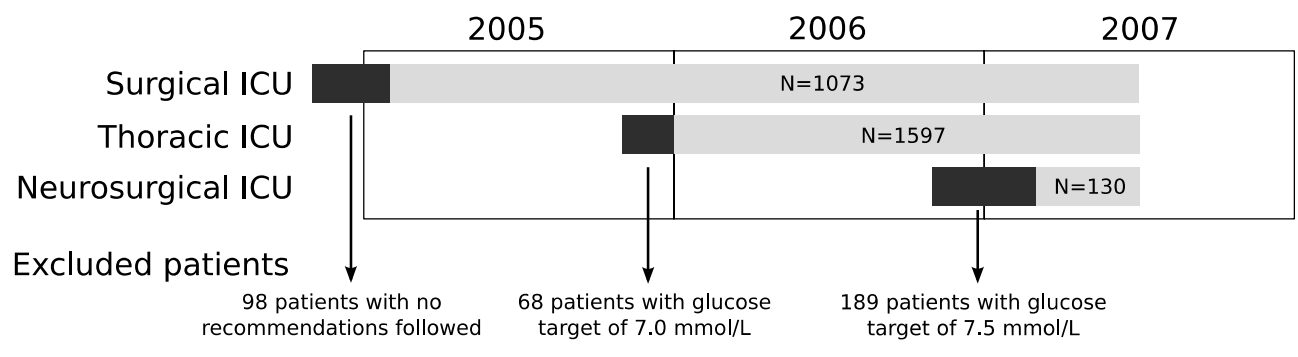


Table 1 Patient characteristics

\begin{tabular}{|c|c|c|c|}
\hline & $\begin{array}{l}\text { Surgical ICU } \\
(n=1,073,38 \%)\end{array}$ & $\begin{array}{l}\text { Thoracic ICU } \\
(n=1,597,57 \%)\end{array}$ & $\begin{array}{l}\text { Neurosurgical ICU } \\
(n=130,5 \%)\end{array}$ \\
\hline Treatment period & Feb. 2005-June 2007 & Jan. 2006-June 2007 & Mar. 2007-June 2007 \\
\hline Age (years) & $62(50-72)$ & $66(57-74)$ & $55(46-65)$ \\
\hline Male sex & $663(62 \%)$ & $1,096(69 \%)$ & $76(62 \%)$ \\
\hline APACHE II & $14(10-19)$ & $14(10-18)$ & $12(7-17)$ \\
\hline \multicolumn{4}{|l|}{ Reason for admission } \\
\hline Cardiothoracic surgery & $13(1.2 \%)$ & $1,303(82 \%)$ & $1(0.8 \%)$ \\
\hline Abdominal surgery & $512(48 \%)$ & $17(1.1 \%)$ & $9(6.9 \%)$ \\
\hline Neurological & $67(6.2 \%)$ & $24(1.5 \%)$ & $103(79 \%)$ \\
\hline Cardiac arrest & $10(0.9 \%)$ & $137(8.6 \%)$ & $1(0.8 \%)$ \\
\hline Trauma & $150(14 \%)$ & $12(0.8 \%)$ & $5(3.8 \%)$ \\
\hline Vascular surgery & $106(10 \%)$ & $18(1.1 \%)$ & $0(0 \%)$ \\
\hline Medical & $57(5.3 \%)$ & $30(1.9 \%)$ & $8(6.2 \%)$ \\
\hline Posttransplant & $45(4.2 \%)$ & $10(0.6 \%)$ & $0(0 \%)$ \\
\hline Miscellaneous & $113(11 \%)$ & $46(2.9 \%)$ & $3(2.3 \%)$ \\
\hline In-hospital mortality & $147(14 \%)$ & $117(7.3 \%)$ & $19(15 \%)$ \\
\hline Total number of patient-days & 8,359 & 5,137 & 752 \\
\hline Admission glucose (mmol/l) & $7.8(6.5-9.5)$ & $8.6(7.3-10)$ & $7.5(6.5-8.9)$ \\
\hline Time to reach target range $(\mathrm{h})$ & $4(0-9)$ & $9(2-13)$ & $2(0-6)$ \\
\hline Glucose after $24 \mathrm{~h}(\mathrm{mmol} / \mathrm{l})$ & $6.7(6.0-7.4)$ & $6.5(5.9-7.2)$ & $6.8(6.1-7.7)$ \\
\hline Glucose SD (mmol/l) & $1.1(0.7-1.7)$ & $1.3(0.9-1.8)$ & $1.0(0.7-1.4)$ \\
\hline
\end{tabular}

Glucose parameters

Glucose measurements were performed in arterial blood samples when an arterial line was present and in venous blood otherwise. All ICUs had a point-of-care blood gas analyzer on which glucose measurements were performed (ABL 700 or 800 series, Radiometer, Copenhagen, Denmark). For each glucose measurement the recommended measurement time was compared with the actual measurement time. We classified these times in lowest, middle two, and highest quartiles. For measurements in each group we determined whether the glucose level was in the desired range, and what the change in insulin pump rate was after that measurement. Actual pump rates were compared to the recommended pump rate at each time point. We determined the linearly interpolated glucose value of each patient at 3-h intervals after admission for the first $48 \mathrm{~h}$ to visualize the general decrease in glucose achieved by GRIP directly after admission to the unit. Low glucose values were scored as mild hypoglycemia $(<3.5 \mathrm{mmol} / \mathrm{l})$ or severe hypoglycemia $(<2.2 \mathrm{mmol} / \mathrm{l})$ and expressed as the proportion of all patients, and as the number of episodes per 1,000 patientdays.

To assess the ability of the program to reduce hyperglycemia we determined the time from admission until the first measurement that was in our target range (4.0-7.5 mmol/l). We also determined the amount of time spent within the target range, both for the full length of stay and for the period after first reaching the target range. We also calculated the hyperglycemic index, a measure of overall hyperglycemia [11]. Recently glucose variability has been proposed as control target of glucose management [12]. We therefore determined blood glucose variability by taking the standard deviation of all measurements of a patient.

\section{Statistics}

All statistics were calculated with $\mathrm{R}$ version 2.2.4 (http://www.r-project.org). Variables are presented as medians and IQR. Comparisons between groups were made with the Mann-Whitney $U$-test, Fisher's exact test, or $\chi^{2}$ test. A $p$-value less than 0.05 was considered statistically significant.

\section{Results}

Glucose control

Median time between patient admission and the first glucose entered into GRIP generating a recommendation was 21 min (6-65). Compliance with GRIP-recommended pump rates was $97 \%$. Compared with the recommended measurement time, the median measurement was $5 \mathrm{~min}$ late (IQR $20 \mathrm{~min}$ early to $34 \mathrm{~min}$ late). Table 2 shows characteristics of glucose measurements and insulin pump interventions for early, on-time, and late measurements. Incidence of measurements less than $4.0 \mathrm{mmol} / \mathrm{l}$ was slightly lower with early than on-time measurements $(p=0.04)$, but late measurements were more often low $(p=0.03)$. Hypoglycemia was uncommon, with $0.86 \%$ of patients experiencing a glucose level lower than $2.2 \mathrm{mmol} / \mathrm{l}$ during any moment of their stay and $7 \%$ for a level of $3.5 \mathrm{mmol} / \mathrm{l}$. Per 1,000 patient-days of ICU stay there were 1.6 measurements lower than $2.2 \mathrm{mmol} / \mathrm{l}$ and 
Table 2 Compliance with measurement time: the lowest (early), middle two (on time), and highest quartile (late). For each category the number of measurements in range is shown and how much the pump rate was adjusted after that measurement. Overall distribution of glucose levels and insulin changes was different for each group ( $\chi^{2}$ test, $\left.p<0.001\right)$

\begin{tabular}{lccc}
\hline & $\begin{array}{l}\text { Early 18,357 } \\
(25 \%)\end{array}$ & $\begin{array}{l}\text { On time 36,805 } \\
(50 \%)\end{array}$ & $\begin{array}{l}\text { Late } 18,026 \\
(25 \%)\end{array}$ \\
\hline Time & $>20$ min early & $-20 \mathrm{~min}$ to +34 min & $>34$ min late \\
Glucose level (percentage & & & \\
of time group) & $0.03 \%$ & $0.03 \%$ & $0.07 \%$ \\
$\quad$ Hypo $(<2.2 \mathrm{mmol} / \mathrm{l})$ & $0.8 \%$ & $1.0 \%$ & $1.3 \%$ \\
Low $(2.2-4 \mathrm{mmol} / \mathrm{l})$ & $74 \%$ & $66 \%$ & $70 \%$ \\
In range $(4-7.5 \mathrm{mmol} / \mathrm{l})$ & $25 \%$ & $33 \%$ & $29 \%$ \\
High $(>7.5 \mathrm{mmol} / \mathrm{l})$ & & & \\
Insulin change (percentage & $6.3 \%$ & $11.9 \%$ & $10.1 \%$ \\
of time group) & $7.3 \%$ & $9.9 \%$ & $9.1 \%$ \\
Decrease $>1 \mathrm{IU} / \mathrm{h}$ & $68 \%$ & $52 \%$ & $58 \%$ \\
Decrease $0.5-1 \mathrm{IU} / \mathrm{h}$ & $10.2 \%$ & $12.5 \%$ & $10.7 \%$ \\
Small change $(-0.5$ to $+0.5 \mathrm{IU} / \mathrm{h})$ & $8.1 \%$ & $13.9 \%$ & $1.7 \%$ \\
Increase $0.5-1 \mathrm{IU} / \mathrm{h}$ & & & \\
Increase $>1 \mathrm{IU} / \mathrm{h}$ & & & \\
\hline
\end{tabular}

14.4 measurements lower than $3.5 \mathrm{mmol} / \mathrm{l}$. For comparison with other studies, which often report the proportion of hypoglycemic measurements instead of patients, the percentage of measurements lower than $2.2 \mathrm{mmol} / \mathrm{l}$ was $0.04 \%$.

Figure 2 graphically shows glucose control directly after admission to the ICU. Admission glucose de- creased from $8.3 \mathrm{mmol} / \mathrm{l}(6.9-9.8)$ to $6.6(6.0-7.4)$ at $24 \mathrm{~h}$ $(p<0.001)$. Time from admission to a value within the desired range was $5.6 \mathrm{~h}(0.2-11.8)$. After that time patients stayed within range for $89 \%(70-100 \%)$ of their remaining stay. Due to the inclusion of a significant number of short stay patients, for which the time to establish initial control represents a relatively large part of their total stay, the
Fig. 2 Median and interquartile range of glucose levels and insulin pump rates during the first $48 \mathrm{~h}$ of ICU stay

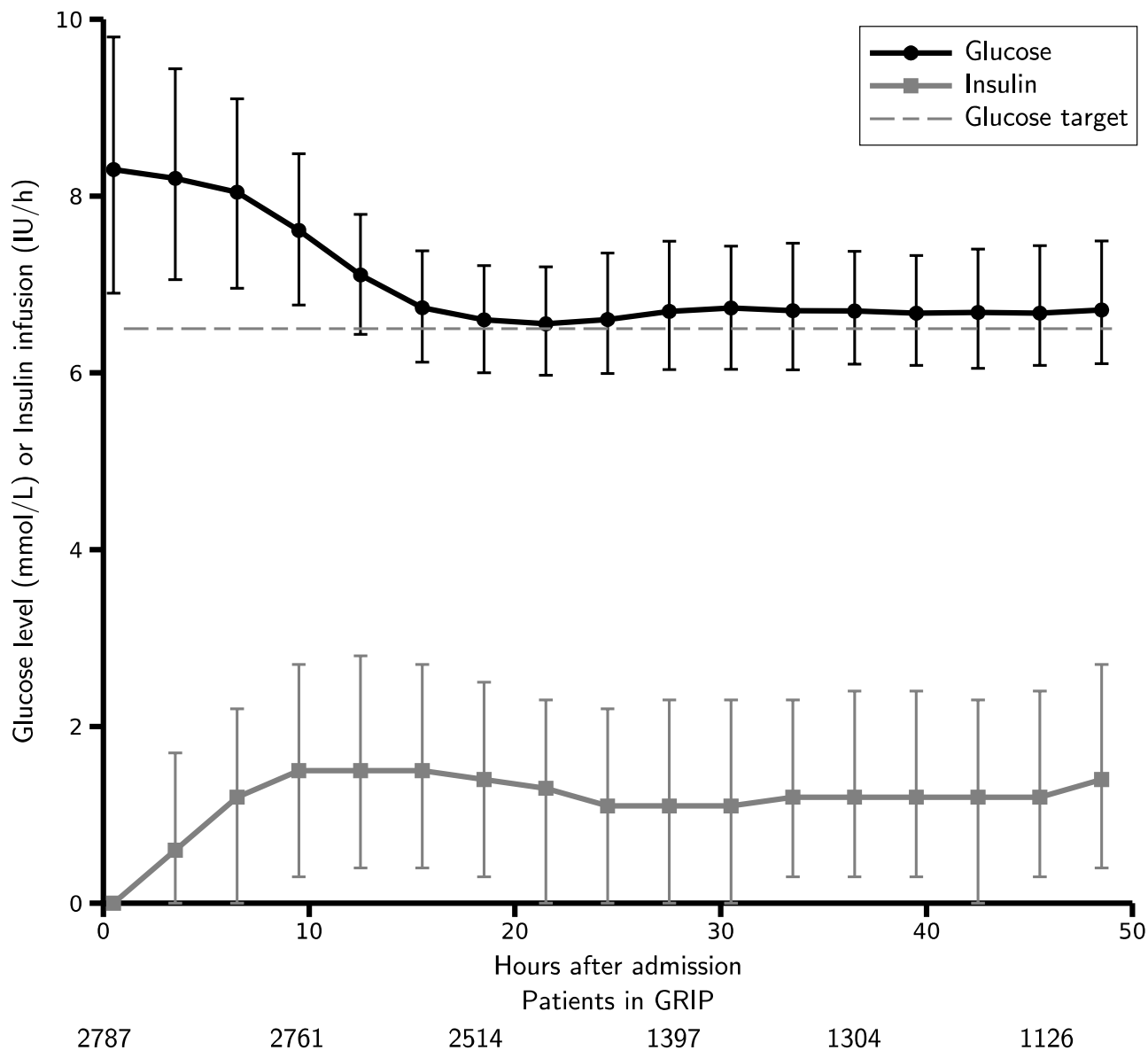


overall time in range was $67 \%$. The hyperglycemic index was $1.24 \mathrm{mmol} / \mathrm{l}(0.8-1.76)$. The patients in the lowest quartile of time in range had higher APACHE II scores, higher insulin doses, less compliance with the recommended insulin rate, more frequent measurements, and a higher incidence of hypoglycemia. Median number of glucose measurements per day of stay was 5.9 (4.7-7.3), i.e., once every $245 \mathrm{~min}$. The glucose variability was $1.22 \mathrm{mmol} / \mathrm{l}(0.8-1.75)$.

\section{Discussion}

This study evaluated computer-assisted glucose control in routine practice over a 3-year period at three ICUs with different patient populations. With a reasonable glucose target level, we found that glucose control was adequate and safe, with low rates of hypoglycemia. Importantly, the protocol was feasible with six measurements per patient per day, and compliance to the protocol was high.

Safety is a major concern in contemporary health care. While the efficacy of glucose control is debated, implementation should be particularly safe [8]. Reducing the possibility of human cognitive failure is a generic way to improve safety in health care [13]. Prior to our study it was shown that standardization by paper protocol improves glucose control, and that computer-assisted protocols are feasible and lead to better compliance than protocols on paper $[14,15]$. Recommendations of pump rates and measurement intervals and the notification of expiration of the interval, combined with the possibility of overruling, provide a flexible standardization of glucose control in the ICU.

Comparison with protocols from the literature is difficult because of wide variations in target glucose levels, patient populations, and metrics of control reported [9]. We performed a literature search to find all computerized glucose protocols designed for ICU patients and tested in at least 20 patients. We summarize these findings in Table 3. Similar to what is reported for paper protocols, reported target ranges, patient populations, and measurement means vary greatly. However, we can conclude that compared with the studies published thus far, the present study is one of the largest to date and compares favorably in terms of occurrence of hypoglycemia and achievement of the target range. Interestingly, only one other published computer protocol [16] aiming at achieving control with a low measurement frequency. This is remarkable, as glucose control with a high measurement frequency is associated with significant costs in terms of nursing effort and supplies [17]. The glucose variability, which has recently been proposed as an important determinant of control [12], was $1.22 \mathrm{mmol} / \mathrm{l}$ in our large cohort. This is lower than the figures published previously, which were $1.7 \pm 1.3$ in survivors and $2.3 \pm 1.6$ in nonsurvivors [12].

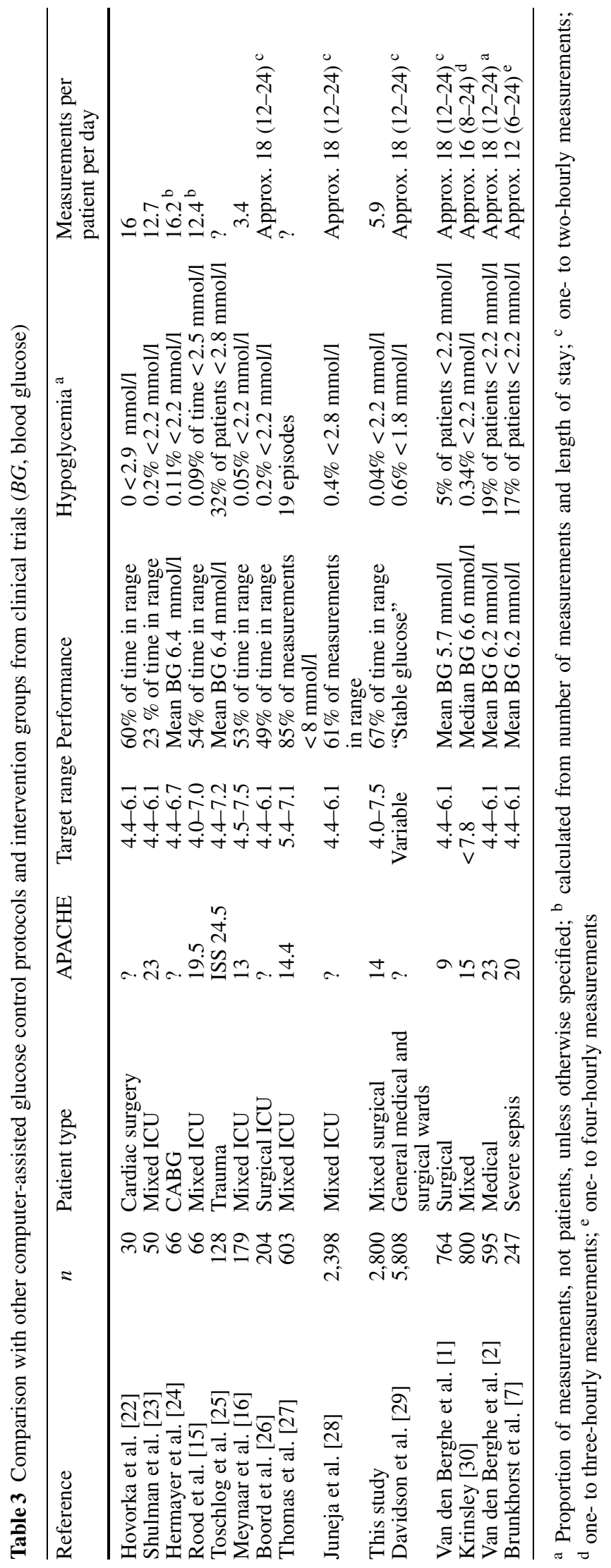


The protocol GRIP used is published as open source, and the program can therefore be used freely by any hospital able to implement the bridge between GRIP and the hospital information system. We recognize that few hospitals have such resources, and we therefore provided a more detailed description of the algorithm in an online supplement, including typical recommendations for two example patients. Computer-based protocols published to date broadly fall into three categories: flow-chart based, empirical formula based, and model based. Most paper protocols that are directly computerized fall into the first category. GRIP uses a formula empirically derived from many protocols and expert knowledge. Model-based approaches model glucose dynamics in different compartments and try to predict future glucose levels and insulin need from that. There have been no direct comparisons of different computer algorithms to date, and more research is needed to identify the best approach.

Our study has a number of strengths. We studied a large number of patients treated in routine practice. This provides a less biased view on true performance and rate of hypoglycemia than studies of glucose protocols in a research setting. The low number of measurements required by GRIP makes the protocol less time consuming than protocols with hourly measurements. The low average number of measurements GRIP requires is mainly caused by the flexibility of the interval algorithm. GRIP performs frequent measurements when needed, but this is counterbalanced by identification of stable periods during a patient's stay (e.g., with steady glucose levels, full caloric intake and low insulin dose) during which much longer intervals can safely be recommended. Another strength is our analysis of actual compliance to the protocol. Prior publications of protocols rarely mention compliance metrics. Good performance attributed to a protocol that is violated often by nurses (by for instance measuring glucose earlier than recommended) can lead to disappointing results when strictly followed at another unit. In our analysis we find no structural violation of the protocol in terms of early and late measurements, and only late measurements were associated with more glucose values that were out of range.

Our study also has a number of limitations. Our choice of target glucose level $(6.5 \mathrm{mmol} / \mathrm{l})$ may be regarded as either low or high, as the optimal target glucose level is currently an open question [18-20]. True adherence to normoglycemia would require a lower target range than we used. The number of measurements asked for by GRIP depends on the expected risk of hypoglycemia, which becomes higher when aiming for a lower target. We therefore expect that a lower target level would increase GRIP's recommended measurement frequency without a significant increase in hypoglycemic episodes, but we have not yet tested this. Clinical decision support tools may be less likely to be successful in a setting in which they were not developed [21]. As the ICUs in our center function independently, and the development process has been limited solely to the surgical ICU, we expect that limitations of generalizability would have been uncovered in the implementation process, or would have been shown by inferior performance on the two other ICUs.

A computer program also brings benefits that we did not study, such as straightforward auditing of performance and easy incorporation of future changes in practice. For instance, when newly published evidence would favor a different target range, a quick adoption of the new preferred practice is possible without going through a learning period for nurses and physicians. In conclusion, our study shows that a computer-assisted protocol can safely and efficiently guide glucose control at intensive care units in routine practice.

Open Access. This article is distributed under the terms of the Creative Commons Attribution Noncommercial License which permits any noncommercial use, distribution, and reproduction in any medium, provided the original author(s) and source are credited.

\section{References}

1. van den Berghe G, Wouters P, Weekers F, Verwaest C, Bruyninckx F, Schetz M, Vlasselaers D, Ferdinande P, Lauwers P, Bouillon R (2001) Intensive insulin therapy in critically ill patients. N Engl J Med 345:1359-1367

2. van den Berghe G, Wilmer A, Hermans G, Meersseman W, Wouters PJ, Milants I, van Wijngaerden E, Bobbaers H, Bouillon R (2006) Intensive insulin therapy in the medical icu. N Engl J Med 354:449-461
3. Vriesendorp TM, DeVries JH, van Santen S, Moeniralam HS, de Jonge E, Roos YB, Schultz MJ, Rosendaal FR, Hoekstra JB (2006) Evaluation of shortterm consequences of hypoglycemia in an intensive care unit. Crit Care Med 34:2714-2718

4. Bhatia A, Cadman B, Mackenzie I (2006) Hypoglycemia and cardiac arrest in a critically ill patient on strict glycemic control. Anesth Analg 102:549-551
5. Sinha $S$, Jayaram R, Hargreaves CG (2007) Fatal neuroglycopaenia after accidental use of a glucose $5 \%$ solution in a peripheral arterial cannula flush system. Anaesthesia 62:615-620

6. Krinsley JS, Grover A (2007) Severe hypoglycemia in critically ill patients: risk factors and outcomes. Crit Care Med 35:2262-2267 
7. Brunkhorst FM, Engel C, Bloos F, Meier-Hellmann A, Ragaller M, Weiler N, Moerer O, Gruendling M, Oppert M, Grond S, Olthoff D, Jaschinski U, John S, Rossaint R, Welte T, Schaefer M, Kern P, Kuhnt E, Kiehntopf M, Hartog C, Natanson C, Loeffler M, Reinhart K, German Competence Network Sepsis (SepNet) (2008) Intensive insulin therapy and pentastarch resuscitation in severe sepsis. N Engl J Med 358:125-139

8. Marik PE, Varon J (2007) Intensive insulin therapy in the ICU: is it now time to jump off the bandwagon? Resuscitation 74:191-193

9. Nazer LH, Chow SL, Moghissi ES (2007) Insulin infusion protocols for critically ill patients: a highlight of differences and similarities. Endocr Pract 13:137-146

10. Vogelzang M, Zijlstra F, Nijsten MW (2005) Design and implementation of GRIP: a computerized glucose control system at a surgical intensive care unit BMC Med Inform Decis Mak 5:38

11. Vogelzang M, van der Horst IC, Nijsten MW (2004) Hyperglycaemic index as a tool to assess glucose control: a retrospective study. Crit Care 8:R122-R127

12. Egi M, Bellomo R, Stachowski E, French CJ, Hart G (2006) Variability of blood glucose concentration and short-term mortality in critically ill patients. Anesthesiology 105:244-252

13. Leape LL, Berwick DM, Bates DW (2002) What practices will most improve safety? Evidence-based medicine meets patient safety. JAMA 288:501-507

14. Kanji S, Singh A, Tierney M, Meggison H, McIntyre L, Hebert PC (2004) Standardization of intravenous insulin therapy improves the efficiency and safety of blood glucose control in critically ill adults. Intensive Care Med 30:804-810
15. Rood E, Bosman RJ, van der Spoel JI, Taylor P, Zandstra DF (2005) Use of a computerized guideline for glucose regulation in the intensive care unit improved both guideline adherence and glucose regulation. J Am Med Inform Assoc 12:172-180

16. Meynaar IA, Dawson L, Tangkau PL, Salm EF, Rijks L (2007) Introduction and evaluation of a computerised insulin protocol. Intensive Care Med 33:591-596

17. Aragon D (2006) Evaluation of nursing work effort and perceptions about blood glucose testing in tight glycemic control. Am J Crit Care 15:370-377

18. Finney SJ, Zekveld C, Elia A, Evans TW (2003) Glucose control and mortality in critically ill patients. JAMA 290:2041-2047

19. Bellomo R, Egi M (2005) Glycemic control in the intensive care unit: why we should wait for NICE-SUGAR. Mayo Clin Proc 80:1546-1548

20. Devos P, Preiser JC (2007) Current controversies around tight glucose control in critically ill patients. Curr Opin Clin Nutr Metab Care 10:206-209

21. Garg AX, Adhikari NKJ, McDonald H, Rosas-Arellano MP, Devereaux PJ, Beyene J, Sam J, Haynes RB (2005) Effects of computerized clinical decision support systems on practitioner performance and patient outcomes: a systematic review. JAMA 293:1223-1238

22. Hovorka R, Kremen J, Blaha J, Matias M, Anderlova K, Bosanska L, Roubicek T, Wilinska ME, Chassin LJ, Svacina S, Haluzik M (2007) Blood glucose control by a model predictive control algorithm with variable sampling rate versus a routine glucose management protocol in cardiac surgery patients: a randomized controlled trial. J Clin Endocrinol Metab 92:2960-2964

23. Shulman R, Finney S, O'sullivan C, Glynne P, Greene R (2007) Tight glycaemic control: a prospective observational study of a computerised decision-supported intensive insulin therapy protocol. Crit Care 11:R75
24. Hermayer KL, Neal DE, Hushion TV, Irving MG, Arnold PC, Kozlowski L, Stroud MR, Kerr FB, Kratz JM (2007) Outcomes of a cardiothoracic intensive care web-based online intravenous insulin infusion calculator study at a medical university hospital. Diabetes Technol Ther 9:523-534

25. Toschlog EA, Newton C, Allen N, Newell MA, Goettler CE, Schenarts PJ, Bard MR, Sagraves SG, Rotondo MF (2007) Morbidity reduction in critically ill trauma patients through use of a computerized insulin infusion protocol: a preliminary study. J Trauma 62:1370-1375

26. Boord JB, Sharifi M, Greevy RA, Griffin MR, Lee VK, Webb TA, May ME, Waitman LR, May AK, Miller RA (2007) Computer-based insulin infusion protocol improves glycemia control over manual protocol. J Am Med Inform Assoc 14:278-287

27. Thomas AN, Marchant AE, Ogden MC, Collin S (2005) Implementation of a tight glycaemic control protocol using a web-based insulin dose calculator. Anaesthesia 60:1093-1100

28. Juneja R, Roudebush C, Kumar N, Macy A, Golas A, Wall D, Wolverton C, Nelson D, Carroll J, Flanders SJ (2007) Utilization of a computerized intravenous insulin infusion program to control blood glucose in the intensive care unit. Diabetes Technol Ther 9:232-240

29. Davidson PC, Steed RD, Bode BW (2005) Glucommander: a computerdirected intravenous insulin system shown to be safe, simple, and effective in 120:618 h of operation. Diabetes Care 28:2418-2423

30. Krinsley JS (2004) Effect of an intensive glucose management protocol on the mortality of critically ill adult patients. Mayo Clin Proc 79:992-1000 